\title{
Culture: collections, compilations, «Actes du Colloque de Paris, 2001-2002», sous la direction de M.-T. Jones-Davies
}

\section{Dario Cecchetti}

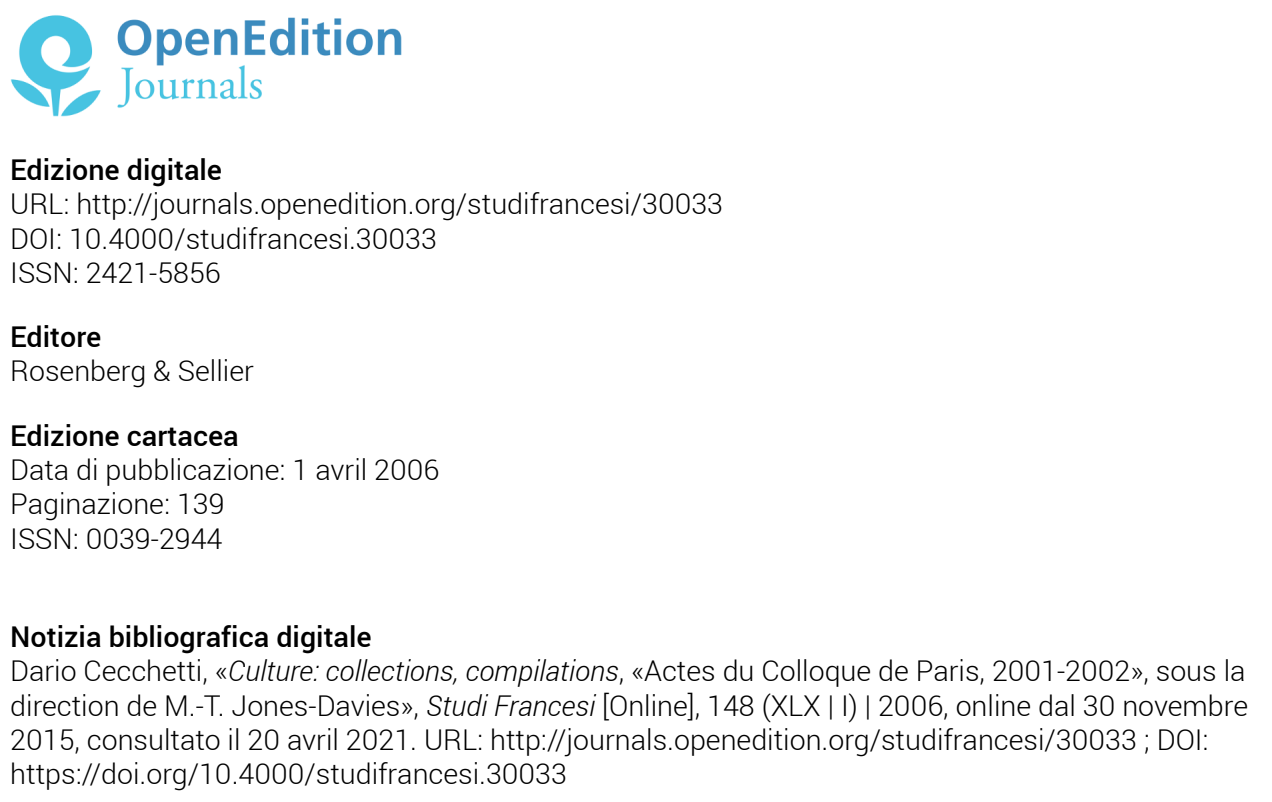

Questo documento è stato generato automaticamente il 20 avril 2021.

\section{(ब) $\odot \Theta \Theta$}

Studi Francesi è distribuita con Licenza Creative Commons Attribuzione - Non commerciale - Non opere derivate 4.0 Internazionale. 


\title{
Culture: collections, compilations, «Actes du Colloque de Paris, 2001-2002», sous la direction de M.- T. Jones-Davies
}

\author{
Dario Cecchetti
}

\section{NOTIZIA}

Culture: collections, compilations, «Actes du Colloque de Paris, 2001-2002», sous la direction de M.-T. JONES-DAVIES, Paris, Champion («Colloques, Congrès et Conférences, S.I.R.I.R.»), 2005, pp. 268.

1 Escono, riunite in un volume, le comunicazioni di due convegni consacrati, nel $2001 \mathrm{e}$ 2002, a Collections e Compilations nel Rinascimento. La passione che induce alla raccolta di oggetti (libri, manoscritti, opere d'arte, curiosità di vario genere) caratterizza la mentalità umanistica, ed ha come parallelo il gusto per le compilazioni letterarie ed erudite (antologie, repertori, dizionari e lavori di tipo enciclopedico) che si molttiplicano lungo tutto il Cinquecento.

2 Le comunicazioni riunite sono le seguenti: M.-T. JonEs-DAvis, Deux collections de livres et leurs vicissitudes (pp. 9-20), E. Paganelli, A Mirror of Renaissance Culture: The Library of William Drummond of Hawthornden (pp. 21-31), J. CÉARD, La notion de corpus: éléments pour un essai de typologie et de définition (pp. 33-43), M.-M. FRAGONARD, Entre exhaustivité et classement raisonné: le R. P. Possevin (pp. 45-68), M.-M. MARTINET, Collections transitives ou réflexives? (pp. 69-77), J.-M. F LAMAND, Lexiques ou anthologies: les premiers dictionnaires gréco-latins imprimés aux XV'-XVI siècles (pp. 79-104), J.-F. MAILLARD, Recueils et anthologies des Estienne: une politique éditoriale? (pp. 105-118), C. MAGNIEN, L'Anthologie ou Recueil de plusieurs discours notables, tirez de divers bons autheurs grecs et latins, par Pierre Breslay, Angevin, Paris, Jean Poupy, 1574 (pp. 119-141), A.-P. P oueY-Mounou, Les Dictionnaires 
d'épithètes, laboratoires de l'«Aptum» (pp. 143-160), J.-CL. MARGOLIN, Compilation, mixture ou sélection? De la farine des anciens à la «farrago epistolarum» d'Érasme (pp. 161-177), G. KILROY, Edmund Campion's Virgilian Epic (pp. 179-193), M. MARRACHE-GOURAUD, La poésie des collection:deux inventaires de cabinets de curiosités (pp. 195-218), R. WILSON, Dyed in Mummy. "Othello» and the Mulberries (pp. 219-243), T. HOENSELAARS, Renaissance Collections of Alexander the Great (pp. 245-259). Come appare anche solo da una rapida scorsa, il fatto collezionistico e compilatorio è affrontato da diverse prospettive, da quella generale a quella individuale esemplificativa. Ł̀ affrontato anche a diversi livelli: quello concettuale di definizione delle nozioni stesse di collezione e compilazione, e questo in un quadro di analisi semantica di storia del termine (Céard) oppure attraverso la riflessione di alcune personalità guida del Rinascimento, quali Erasmo (Margolin); quello descrittivo di singole opere o generi (Flamand, Maillard, Magnien, PoueyMounou); quello di ricostruzione del collezionismo e di fondi librari (Jones-Davies, Paganelli, Fragonard, Martinet). Siamo in genere in presenza di contributi di grande interesse e originali, utili alle indagini sulla mentalità rinascimentale. 